\title{
Interprovincial Migration and Human Capital Formation in China*
}

\author{
Yui Suzuki and Yukari Suzuki
}

Received 4 April 2013; accepted 12 April 2015

\begin{abstract}
We examine how the rising interprovincial migration of individuals with diverse educational backgrounds affected human capital formation in China in the 1990s. We find that gross outflow migration of those with higher and lower levels of education, respectively, has human capital incentive and disincentive effects. Our estimates suggest that the incentive effect eclipses the disincentive effect in general; however, a surge of migration, particularly among less educated groups, implies more of a disincentive effect in China in the 1990s. We also find that changes in the relative labor supply resulting from net outflow migration mitigate a direct brain drain by both encouraging and discouraging school enrolments.
\end{abstract}

Keywords: brain drain, China, human capital, migration, schooling.

JEL classification codes: J24, J61, O15.

doi: 10.1111/asej.12089

\section{Introduction}

There has been concern that the emigration of high-skilled workers from developing countries to developed countries would have adverse effects on the developing countries and widen North-South inequality (Beine et al., 2001). Rich countries hence become richer at the expense of poor countries who suffer as a result of a reduction in human capital, or a 'brain drain'. Since the 1970s, institutional settings such as domestic labor market rigidity and fiscal and technological externalities have been studied to explore the negative welfare consequences of the brain drain in developing countries (e.g. Bhagwati and Hamada, 1974; McCulloch and Yellen, 1977). Later in the 1990s, further studies employing endogenous growth frameworks reached more or less the same conclusion with regards to the negative effect of the migration of highly skilled workers from developing countries (e.g. Miyagiwa, 1991; Haque and Kim, 1995). These arguments start with a self-

*Yui Suzuki (corresponding author): Faculty of Economics, Finance Department, Musashi University, 1-26-1 Toyotama-kami Nerima-ku, Tokyo 176-8534 Japan. Email: yui-szk@cc.musashi.ac.jp. Yukari Suzuki: Department of Economics, University of Michigan, 611 Tappan St. Ann Arbor, MI 48109-1220 United States. Email: yukaris@umich.edu. The authors are grateful to Charles Brown, Albert Park, Jan Svejnar and anonymous referees for their guidance and helpful comments. We also thank the Institute of Population and Labor Economics, Chinese Academy of Social Sciences for providing us with the aggregated migration flow data tabulated based on the census data. 
evident truth: migration inevitably alters the geographical allocation of human capital. In this context, destination economies are the winner, gaining human capital embodied in migrants, and source economies are the loser, when, as is often the case, people drained from the economy are highly educated.

However, since the late 1990s, a series of papers have challenged the pessimistic brain drain argument, by suggesting that the emigration of high-skilled workers from developing countries can be beneficial for the source countries. This claim is supported by an important point neglected in the brain drain argument: a country's pre-migration human capital stock is endogenous to the prospect and realization of migration. Some studies assert that there may be beneficial impacts of international migration on source countries: that there is a 'brain gain', through uncertainty in migration (Mountford, 1997; Stark et al., 1998; Beine et al., 2001, 2008), migrants' remittances (Edwards and Ureta, 2003; Hanson and Woodruff, 2003; Borraz, 2005; Yang, 2008), return migration (Borjas and Bratsberg, 1996; Stark et al., 1997) and migrants' networks (Kanbur and Rapoport, 2005). These findings suggest that source countries can alleviate the direct loss due to brain drain by increasing human capital investment through a variety of channels. ${ }^{1}$

These new insights into international migration highlight the possibility that domestic migration influences the total amount of human capital available at the national level as well as impacting the distribution of human capital across regions. If migration does not affect the incentive for new human capital formation, migration within a national territory, unlike the international case, would merely alter the regional distribution of human capital in a country. However, this is not true when we take into account the brain gain: internal migration alters new human capital investment and, thus, can change the overall human capital stock at the national level. Because there are more changes of residence through domestic migration, domestic migration can have a greater influence on new human capital formation.

The present study examines how the internal migration of individuals with diverse educational backgrounds affects human capital formation in source economies and explores the implications for the development of regional and national economies. According to Beine et al. (2001) the prospects of migration foster investments in education when international migrants are positively selected based on education and skills; we apply this conjecture to domestic migration. A better chance of migration for the educated, who seek higher returns to their human capital in the destination, provides the younger generation with greater incentive to enroll into schools in the source economy. Following Docquier and Rapoport (2004), we refer to this beneficial effect as the human capital incentive effect. However, we must be mindful of one point for our purpose: domestic migration differs from international migration, discussed in Beine et al. (2001), in that those with higher skill levels and education do not necessarily comprise the majority of migrants. A higher prospect of migration for the less educated can have an

1 Docquier and Rapoport $(2004,2012)$ review literature on the brain drain and brain gain through international migration, including recent empirical works.

(C) 2016 East Asian Economic Association and John Wiley \& Sons Australia, Ltd 
adverse effect on school enrollments because it pushes up the opportunity cost of education. We refer to such a negative effect as the human capital disincentive effect.

The goal of the present paper is to empirically investigate whether and to what extent the prospects of migration for individuals with diverse educational qualifications reinforce and/or attenuate the incentive to attend school. We investigate the case of China from the late 1980s to the 1990s and find both human capital incentive and disincentive effects. The estimates for the positive effects are greater than the negative effects, suggesting that, when people make their school enrollment decisions, they tend to respond more to the prospect of migration with higher educational achievements to increase education continuance rates. However, it is shown that the intensification of the interprovincial migration in China in the 1990s had a rather negative effect on the whole, because the mobility of the less educated workers grew at a much faster pace than that of the more educated workers.

An alternative theory of a mechanism through changes in the relative labor supply is also investigated. Net outflow migration of individuals of a certain education level brings about excess demand for workers with the corresponding qualification in the source economy and, thus, results in a relatively higher wage premium for these workers. Assuming partial complementarities among workers with diverse educational backgrounds, net outflow migration encourages school enrollment in the corresponding schools and/or discourages enrollment in the schools that provide a higher level of education. We identify both effects and show that this mechanism alleviates the direct brain drain effect in source provinces and contributes to stemming the tide of disparities in human capital among provinces.

The remainder of this paper is organized as follows. Section II reviews the development of mass interprovincial migration in China in the 1990s. Section III estimates the human capital incentive and disincentive effects of gross outflow migration. Section IV discusses relative labor supply effects and Section V concludes.

\section{Interprovincial Migration in China}

This section considers the evolution of mass interprovincial migration in China in the 1990s. Data on interprovincial migration are derived from population censuses conducted in 1990 and 2000. We use the numbers of migrants across province borders and the numbers of those who remain, aged $17-60$, who were not in school in the census years to estimate migration rates. ${ }^{2}$ We estimate the overall interprovincial migration rates as well as the migration rates categorized by education backgrounds. Our sample comprises 29 provinces in China. ${ }^{3}$ Coastal provinces include the 12 provinces of Beijing, Liaoning, Tianjin, Hebei, Shandong, Jiangsu, Shanghai, Zhejiang, Fujian, Guangdong, Hainan and Guangxi,

2 Details on the definition of migrant are discussed in Section III.

3 We exclude Tibet due to lack of consistent data, and treat Chongqing, which was a part of Sichuan Province until 1997, as a part of Sichuan Province.

(C) 2016 East Asian Economic Association and John Wiley \& Sons Australia, Ltd 
Table 1 Gross outflow migration rates by education category and provinces (\%)

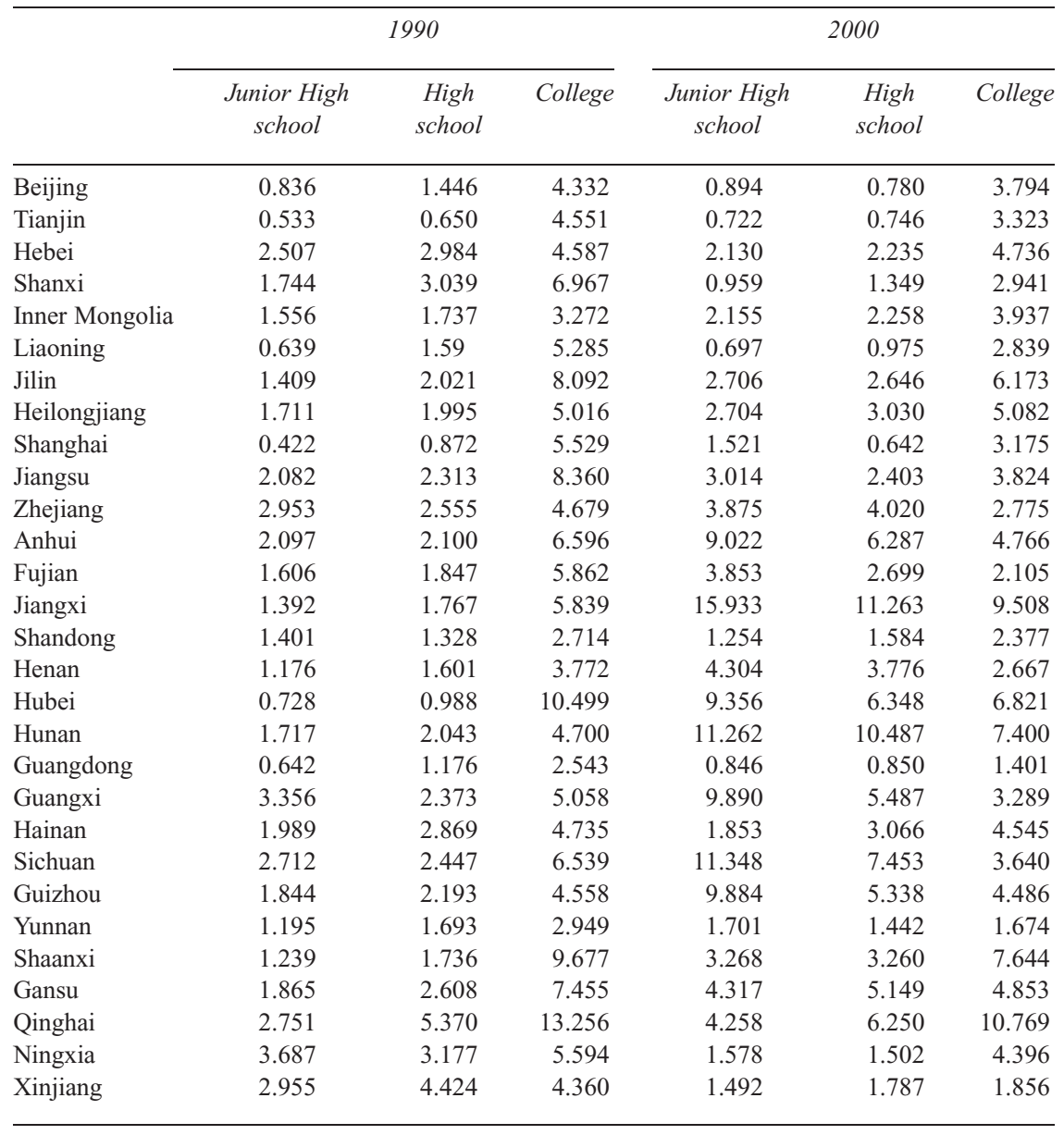

and the other 17 provinces are inland provinces. The descriptive data on gross outflow migration rates by education category and by province appears in Table 1.

Over the past few decades, large and widening inequality in China has given strong economic inducement for people to migrate from poorer provinces to richer provinces. Since the Communist Party made a policy decision on reform and opening-up in late 1978, China has undergone tremendous changes to become the factory of the world. Rapid industrialization enlarged the disparities in income between coastal and inland provinces, ${ }^{4}$ and deepening of reforms

$4 \mathrm{Fu}(2004)$ documents that the ratio of average GDP per capita in coastal regions to that in inland regions was high, at 1.67, in 1990 and grew even higher, to 2.08, by 1999 .

(C) 2016 East Asian Economic Association and John Wiley \& Sons Australia, Ltd 
substantially increased the dispersion of schooling returns across cities by the mid-1990s, indicating a segmentation of the regional labor market (Yang, 2005). The uneven economic growth and returns to schooling have led to increased interprovincial migration.

Under such circumstances, China's unique household registration system, hukou, has been relaxed to increase the mobility of workers. In addition, such increased mobility was first observed disproportionately among the workers with higher education. This, indeed, provides an ideal natural experimental case for our purposes.

The Chinese Government introduced the hukou system in 1958 to limit mass migration to cities and, thereby, ensure public order. A worker who planned to move out from his/her registered place into urban areas and to take up non-agricultural work had to apply through the relevant bureaucracies, because those who worked outside their authorized domain or geographical area were not entitled to receive basic social welfare, including food rations, health care and education. However, the number of people allowed to make such changes in their registration places was strictly limited and the beneficiaries were mostly those with high educational backgrounds and skills, such as college graduates. Thereby, the hukou system discouraged mass migration from rural to urban areas as well as migration among cities, particularly from medium and small cities to major cities, and, therefore, interregional migration has historically been tightly constrained. ${ }^{5}$

Nevertheless, rapid and regionally uneven economic development boosted interprovincial migration from interior to coastal provinces by the 1990s. As economic development created strong demand for workers in cities and coastal provinces, officials gradually started relaxing their enforcement of this registration system and cautiously encouraging migration from interior rural areas. The number of interprovincial migrants, excluding those who enrolled in schools in the census years, tripled, from 8.8 million in 1990 to 28.5 million in 2000. Furthermore, a clear pattern of migrant flow from inland to coastal provinces emerged in the 1990s. Fig. 1a and b show that there is a striking asymmetry in the development of mobility between inland and coastal provinces: the gross outflow migration rate increased in inland provinces and the gross inflow migration rate increased in coastal provinces. While interprovincial migration was less widespread and moved fairly evenly between coastal and inland provinces around 1990, coastal provinces came to attract massive amounts of migrants and inland provinces became the suppliers of human capital by 2000. In particular, inflows of migrants were distinct in Beijing, Shanghai and Guangdong by 2000.

In addition, over this decade the interprovincial migration grew unevenly among education categories. The national average migration rate for those who

5 Whalley and Zhang (2007) argue that hukou restrictions have played a significant role in supporting inequality in China over the past 20 years. 
Figure 1 (a) Evolution of mass migration in the 1990s (Coastal Provinces) gross inflow and outflow migration rates for all migrants in 1990 and 2000. (b) Evolution of mass migration in the 1990s (Inland Provinces) gross inflow and outflow migration rates for all migrants in 1990 and
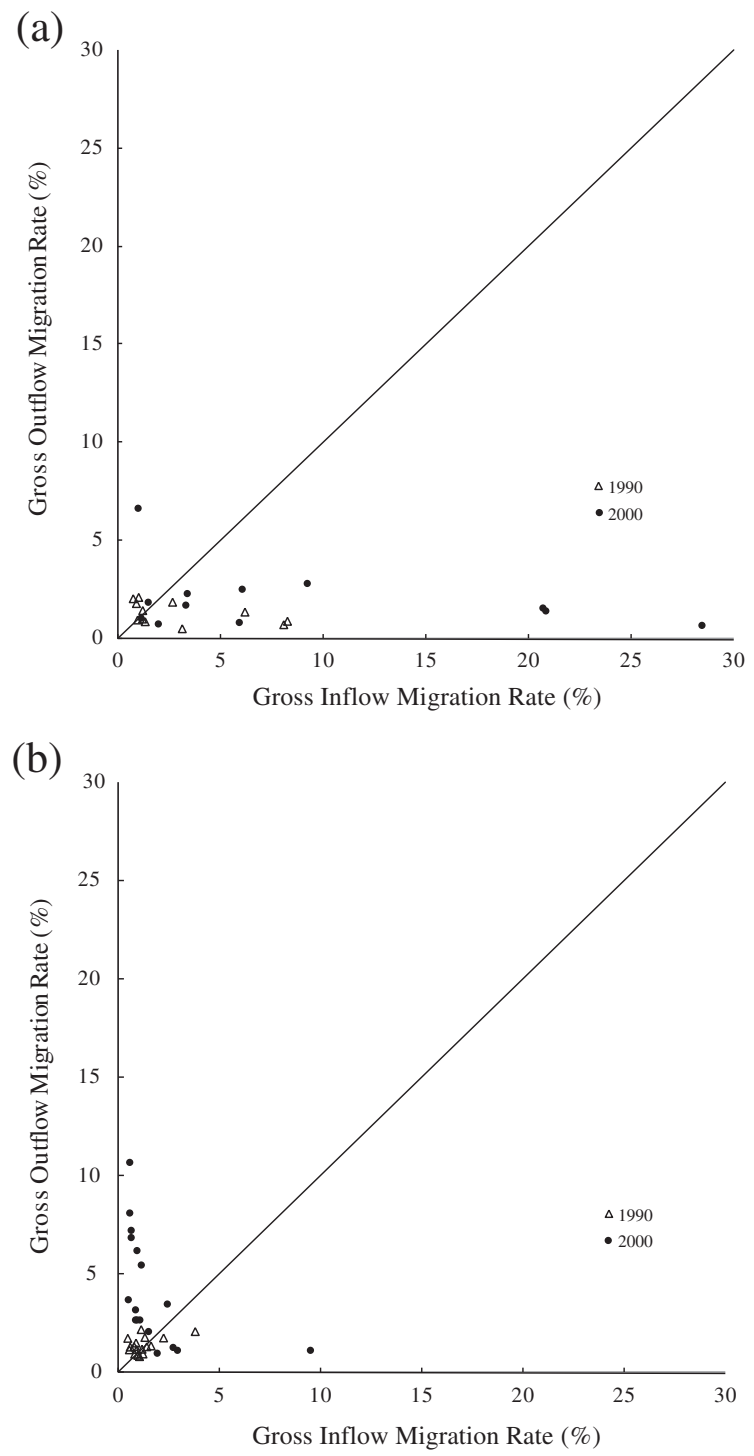

had completed high school, junior high school, and primary school or below, respectively, increased from 1.9 to 3.8 percent, 1.7 to 5.0 percent and 0.8 to 2.3 percent from 1990 to 2000, while that for those with college degrees decreased 
slightly, from 5.6 to 4.0 percent. $^{6}$ The mobility of college graduates was conspicuous and significant in 1990; however, this had changed by 2000 . The higher migration rate for college graduates in 1990 was presumably caused by the discrimination in the registration system. Nevertheless, rapid and lopsided economic growth in the coastal region provided overpowering economic incentive for high school and junior high school graduates to migrate to coastal provinces in the $1990 \mathrm{~s}$, and migration became more common for these less educated groups by 2000. It is well-recognized that many unregistered migrants in urban areas have faced barriers to educating their children and accessing health care. However, high school and junior high school graduates have been migrating interprovincially despite unfavorable treatment for many under the hukou system.

Furthermore, we observe some asymmetry in the geographical composition of migration among educational levels attained. Table 2 categorizes interprovincial migrants by schooling into four groups according to the source and destination provinces: migrants between coastal provinces $(\mathrm{CC})$; from coastal provinces to inland provinces (CI); from inland provinces to coastal provinces (IC); and between inland provinces (II). While CC, IC and II accounted for approximately 30 percent of all migrants in 1990, the share of IC grew substantially to 63 percent in 2000, which is consistent with the findings of Lin et al. (2004). To be more precise, these features were also valid for migrants who had completed junior high school and high school; yet the share of IC for migrants with college degrees increased by only 10 percentage points. These findings suggest that,in the 1990s, the incentive to migrate from inland to coastal provinces was greater for residents with educational backgrounds higher than junior high school, and, in particular, the incentive was stronger for those who had completed junior high school and high school.

Because the censuses define migration as a change in place of residence within 5 years, college graduates who grew up in province A, attended college in province B and stayed in province B may not be counted as interprovincial migrants. In contrast, those who grew up in province $A$, attended college in province $B$ and went back to work in province A are likely to be counted as migrants. The provinces of big cities such as Beijing and Shanghai have disproportionately greater numbers of higher education institutions. As a consequence, a nonnegligible proportion of college students are considered to have grown up in provinces other than the locations of their colleges. Although colleges are no longer as strongly concentrated in the big cities (the ratio of in-college migrants to the three large cities of Beijing, Tianjin and Shanghai vis-à-vis all in-college migrants substantially decreased from 67 percent in 1990 to 26 percent in 2000), the ratio of college students from other provinces to all college students is non-negligible and stable at around 20-30 percent. Unfortunately, the census data does not allow

6 In both years, migration rates were found to be higher for those who had attended educational institutes higher than junior high school. 
Table 2 Shares of coastal and inland provinces as the destinations and sources of migration (\%)

\begin{tabular}{lccrcr}
\hline & Year & CC & CI & IC & II \\
\hline All & 1990 & 27.26 & 13.99 & 32.13 & 26.62 \\
College & 2000 & 18.30 & 4.47 & 63.44 & 13.79 \\
& 1990 & 30.67 & 11.99 & 40.81 & 16.52 \\
High School & 2000 & 28.76 & 7.45 & 49.78 & 14.01 \\
& 1990 & 27.28 & 15.96 & 31.48 & 25.28 \\
Junior High School & 2000 & 19.00 & 5.64 & 62.28 & 13.08 \\
& 1990 & 30.08 & 14.08 & 31.01 & 24.83 \\
& 2000 & 18.85 & 4.03 & 66.16 & 10.96 \\
\hline
\end{tabular}

The shares are calculated by the percentages of migrants in the following four groups: CC, CI, IC, II. $\mathrm{CC}$, migrants from coastal provinces to coastal provinces; CI, migrants from coastal provinces to inland provinces; IC, migrants from inland provinces to coastal provinces; II, migrants from inland provinces to inland provinces.

us to trace how much college graduates stay in the provinces where their colleges are located and how many move back to the provinces where they grew up. This poses a caveat in analyzing the college enrollment rates and the migration rates of those with college degrees.

\section{Estimating Human Capital Incentive and Disincentive Effects}

In the present study we aim to identify the effects of mass migration on new human capital investment in source economies. The case of China is explored based on the understanding that rapid and uneven economic development accelerated interprovincial migration, and there is a disproportion in the migration of individuals on the basis of educational background. Because our goal includes clarifying whether prospects of migration with superior/inferior education are accelerators and/or hindrances of new human capital formation on the whole at national level, we employ provincial-level datasets. With respect to rural-urban migration, de Brauw and Giles (2005) suggest a negative relationship between migration opportunity and high school enrollment in 52 villages in four provinces (Shanxi, Jiangsu, Anhui and Henan).

We examine whether there are positive and/or negative effects of gross outflow migration on new human capital formation in source provinces. As outlined in the introduction, gross outflow migration can have both human capital incentive and disincentive effects: better prospects of securing higher income through migration for the educated (less educated) increase (decrease) incentive to enroll in schools and, thus, mass migration accelerates and/or hinders new human capital formation depending on the educational backgrounds of migrants. A simple theoretical model developed in the Appendix illustrates these mechanisms. To identify these effects at diverse school levels, we estimate the following equation: 


$$
\begin{aligned}
& E D U_{i, t}=\beta_{0}+\beta_{1} M I G O_{\mathrm{i}, \mathrm{t}^{\tau}}+\beta_{2} P C G D P_{\mathrm{i}, \mathrm{t}}+\beta_{3} U N E M P_{\mathrm{i}, \mathrm{t}} \\
& +\beta_{4} N U M S C H O O L_{i, \mathrm{t}}+\left(\gamma_{i}\right)+v_{i, t},
\end{aligned}
$$

where EDU, MIGO, PCGDP, UNEMP, NUMSCHOOL, $\gamma$ and $v$, respectively, are the education attainment rate, the gross outflow migration rate, the real GDP per capita at 1990 constant prices, the unemployment rate, the number of schools per unit of land area $\left(10000 \mathrm{~km}^{2}\right)$, the unobserved province effect and an error term. The subscript $i$ refers to provinces. The subscripts $t$ and $\widetilde{t}$, respectively, denote the census years (i.e. 1990 and 2000) ${ }^{7}$ and the 5 years between census years and the inaugural years of the 5-year periods considered in defining migration (i.e. $1985-1990$ and $1995-2000)$. We include three education categories of junior high school, high school and college, ${ }^{8}$ because the nationwide enrollment rate of school-age children into primary school was high, at 97.8 percent in 1990 and 99.1 percent in 2000, and internal migrants in China tend to have attained an education level higher than junior high school. We define $E D U$ as the percentage of students who go on to higher education institutions vis-à-vis graduates of primary school. We estimate $E D U$ from the numbers of graduates from and new enrollments into relevant education institutions in year $t$ based on the premise that a typical newly enrolling student into an education category (e.g. high school) graduates from a lower category (junior high school) in the same year. The education attainment rate for high school $(E D U H)$, for example, is computed as a product of the ratio of new enrollments into high school to graduates from junior high school and the ratio of new enrollments into junior high school to graduates from primary school. Note that $E D U$ is, thus, free of the bias due to the differences in the cohort sizes of different ages, unlike the mere ratio of new enrollments into high school to graduates from primary school. As our purpose is to investigate the incentive to enroll in schools when people observe difference in the prospects of migration on the basis of educational background, we consider working-age migrants and non-migrants in constructing $M I G O$. To be exact, we pick out non-student migrants and non-migrants aged $17-60$ in census years by ruling out younger migrants aged under 17 who did not graduate from primary schools 5 years previously $(1985 / 1995)$ and older migrants aged above 60 . Migration is defined as a change of residence within 5 years determined from the dates of population censuses, which are 1 July 1990 and 1 November 2000. ${ }^{9}$ Specifically, both censuses count a person as a migrant when he/she changes his/her residence together with his/her registration. When a person changes his/her residence without changing his/her registration, he/she is counted as a migrant only if he/she leaves the place of registration for longer than a specified

7 We use 3-year averages between 1990-1992/2000-2002 for EDU, PCGDP, UNEMP and NUMSCHOOL to diffuse potential passing fluctuation in 1990/2000.

8 Junior high school represents junior secondary schools; high school includes senior secondary, specialized secondary and vocational schools; college covers junior college, college and graduate schools. 9 In the 2000 census, the relevant questions were asked in long form, with a sampling ratio of 9.5 percent. 
minimum period of time. ${ }^{10}$ We handle numbers of migrants categorized by educational levels, namely junior high school, high school and college, ${ }^{11}$ and define migration rates as the ratio of numbers of migrants to working-age population not in-school with respective educational backgrounds 5 years ago, Note that we avoid a simultaneity bias and clarify the causality between prospects of migration and new school attendance by employing a flow base indicator of new human capital formation $(E D U)$ in the successive years of migration on the left-hand side of the equation. GDP per capita and the unemployment rate reflect economic conditions, while the number of schools per unit of land area indicates the accessibility to school. We estimate Equation (1) using OLS, the random effects model and the fixed effects model. ${ }^{12}$ As unobserved province effects may or may not be correlated with explanatory variables, we apply Hausman's test and report the estimates that pass this test. Data are from population censuses conducted in 1990 and 2000, the China Statistical Yearbook (NBS, various years), Comprehensive Statistical Data and Materials on Fifty Years of New China (NBS, 1999) and the China Population Statistics Yearbook (NBS, various years). All variables are in natural logarithms. Table 3 defines all the variables. Table 4 summarizes the statistics.

The estimates, reported in Table 5, support the presence of human capital incentive and disincentive effects. ${ }^{13}$ We estimate the effects on school enrollments for three education categories as a result of the gross outflow migration of individuals with diverse levels of education: (i) all levels equal to or higher than the corresponding level of education attained (e.g. high school and college) and lower level of education attained (e.g. junior high school and below); (ii) the corresponding level of education attained itself (e.g. high school); and (iii) the corresponding level of education attained (e.g. high school) and one level lower (e.g. junior high school). ${ }^{14}$ We obtain statistically significant estimates of $\beta_{1}$, ranging from 0.378 to

10 This minimum time period is 1 year in the 1990 census but it is reduced to 6 months in the 2000 census. Therefore, the number of migrants in 1990 appears to be understated if we follow the definition in the 2000 census.

11 We categorize those who have completed junior secondary schools under 'junior high school', those who have completed senior secondary and specialized secondary schools under 'high school' and those who have completed junior colleges, colleges and graduate schools under 'college'.

12 We are aware of possible unobserved province effects $(\gamma)$. For instance, if people in a province place higher value on education than in other provinces, education attainment will be positively correlated with the human capital stock in year $t$, regardless of the migration prospect. However, when the Chinese Government reduces barriers to migration, the educated are more likely to migrate, which could statistically lead to a positive correlation between $M I G O$ and the EDU.

13 The effects of domestic migration on human capital formation for a few main destination provinces such as Beijing, Shanghai and Guangdong can be quite different from those for inland provinces, the main source provinces of domestic migration in China. Therefore,we re-run the regressions with the data excluding Beijing, Shanghai and Guangdong (results are available upon request). The signs and statistical significances of the estimates, particularly the ones for the migration rates by category (our main interest in the empirical analysis), are shown to be robust.

14 We avoid including migration rates of all the degree levels taking into account the multicollinearity problem. Migration rates in adjacent educational categories tend to be highly correlated. 
Table 3 Definitions of variables

\begin{tabular}{lll}
\hline Variables in & Variables in & Definition \\
equations & regressions &
\end{tabular}

\begin{tabular}{|c|c|c|}
\hline \multirow[t]{20}{*}{$M I G_{i}$} & $M I G O$ & $\begin{array}{l}\text { Number of all migrants from province } i \text { to other } \\
\text { provinces within the previous } 5 \text { years (1985-1990/ } \\
\text { 1995-2000)/(Population in province } i \text { in 1990/2000 } \\
+ \text { Number of all net outflow migrants in 1985-1990/ } \\
\text { 1995-2000) (\%) }\end{array}$ \\
\hline & $M I G I$ & $\begin{array}{l}\text { Number of all migrants moving from other provinces } \\
\text { to province } i \text { within the previous } 5 \text { years }(1985-1990 / \\
1995-2000) /(\text { Population in province } \mathrm{i} \text { in } 1990 / 2000 \\
\text { + Number of all net outflow migrants in } 1985-1990 / \\
\text { 1995-2000) }(\%)\end{array}$ \\
\hline & $M I G N$ & $M I G O / M I G I$ \\
\hline & EDUCATIONMIGO & $\begin{array}{l}\text { Number of migrants at each educational level from } \\
\text { province } i \text { to other provinces within the previous } \\
5 \text { years (1985-1990/1995-2000)/(Number of people at } \\
\text { each educational level in province } i \text { in } 1990 / 2000 \\
+ \text { Number of net outflow migrants at each educational } \\
\text { level from province } i \text { in 1985-1990/1995-2000) (\%) }\end{array}$ \\
\hline & EDUCATIONMIGI & $\begin{array}{l}\text { Number of migrants at each educational level from } \\
\text { other provinces to province } i \text { within the previous } \\
5 \text { years (1985-1990/1995-2000)/(Number of people } \\
\text { at each educational level in province } i \text { in } 1990 / 2000 \\
+ \text { Number of net outflow migrants at each educational } \\
\text { level from province } i \text { in 1985-1990/1995-2000) (\%) }\end{array}$ \\
\hline & EDUCATIONMIGN & EDUCATIONMIGO/EDUCATIONMIGI \\
\hline & $B M I G O$ & $E D U C A T I O N=$ primary schools and below \\
\hline & $B M I G N$ & \\
\hline & $J M I G O$ & $E D U C A T I O N=$ junior secondary schools \\
\hline & $J M I G N$ & \\
\hline & $H M I G O$ & $E D U C A T I O N=$ senior secondary or specialized \\
\hline & $H M I G N$ & secondary schools \\
\hline & CMIGO & $E D U C A T I O N=$ junior colleges, colleges, or graduate \\
\hline & $C M I G N$ & schools \\
\hline & $B M I G O$ & $E D U C A T I O N=$ junior secondary schools and above \\
\hline & $B M I G N$ & \\
\hline & ABOVEJ MIGO & $E D U C A T I O N=$ junior secondary schools and above \\
\hline & ABOVEH MIGO & $\begin{array}{l}E D U C A T I O N=\text { senior secondary or specialized } \\
\text { secondary schools and above }\end{array}$ \\
\hline & BELOWH MIGO & $E D U C A T I O N=$ junior secondary schools and below \\
\hline & BELOWC MIGO & $\begin{array}{l}E D U C A T I O N=\text { senior secondary or specialized } \\
\text { secondary schools and below }\end{array}$ \\
\hline$P C G D P_{i}$ & $P C G D P$ & $\begin{array}{l}\text { GDP per capita of province } i \text { at } 1990 \text { constant prices } \\
\text { (yuan, in 1990-1992/2000-2002) }\end{array}$ \\
\hline$E D U_{i}$ & EDUJ & $\begin{array}{l}\text { Average percentage of students who enter into junior } \\
\text { secondary schools in province } i \text { vis-à-vis graduates of } \\
\text { primary schools (1990-1992/2000-2002) (\%) }\end{array}$ \\
\hline
\end{tabular}


Table 3 (continued)

\begin{tabular}{|c|c|c|}
\hline $\begin{array}{l}\text { Variables in } \\
\text { equations }\end{array}$ & $\begin{array}{l}\text { Variables in } \\
\text { regressions }\end{array}$ & Definition \\
\hline & & $\begin{array}{l}\text { Number of new enrollment in junior secondary } \\
\text { schools/Number of graduates from primary schools } \\
* 100\end{array}$ \\
\hline & $E D U H$ & $\begin{array}{l}\text { Average percentage of students who enter into senior } \\
\text { secondary, specialized secondary, or vocational } \\
\text { schools in province } i \text { vis-à-vis graduates of primary } \\
\text { schools (1990-1992/2000-2002) (\%) } \\
\text { (number of new enrollment in senior secondary, } \\
\text { specialized secondary, or vocational schools / number } \\
\text { of graduate from junior secondary schools) * EDUJ }\end{array}$ \\
\hline & $E D U C$ & $\begin{array}{l}\text { Average percentage of students who enter into } \\
\text { institutes of higher education in province i vis-à-vis } \\
\text { graduates of primary schools (1990-1992/2000- } \\
\text { 2002) (\%) }\end{array}$ \\
\hline & & $\begin{array}{l}\text { (number of new enrollment in institutes of higher } \\
\text { education/number of graduates from senior } \\
\text { secondary, specialized secondary, or vocational } \\
\text { schools) *EDUH }\end{array}$ \\
\hline$U N E M P_{i}$ & $U E M P$ & $\begin{array}{l}\text { Average urban registered unemployment rate in } \\
\text { province } i(1990-1992 / 2000-2002)(\%)\end{array}$ \\
\hline \multirow[t]{3}{*}{$\mathrm{NUMSCHOOL}_{i}$} & $N U M J$ & $\begin{array}{l}\text { Number of junior secondary schools per land area (10 } \\
\left.000 \mathrm{~km}^{2}\right)(1990-1992 / 2000-2002)\end{array}$ \\
\hline & $N U M H$ & $\begin{array}{l}\text { Number of senior secondary, specialized secondary } \\
\text { and vocational schools per land area }\left(10000 \mathrm{~km}^{2}\right) \\
(1990-1992 / 2000-2002)\end{array}$ \\
\hline & $N U M C$ & $\begin{array}{l}\text { Number of institutes of higher education per land area } \\
\left(10000 \mathrm{~km}^{2}\right)(1990-1992 / 2000-2002)\end{array}$ \\
\hline
\end{tabular}

0.475 for college enrollment, from 0.264 to 0.297 for high school enrollment, and from 0.033 to 0.075 for junior high school enrollment, which suggest positive effects of gross outflow migration with equal or superior educational backgrounds on the enrollment into the corresponding school. ${ }^{15}$ In contrast, we notice that the estimates of $\beta_{1}$ are mostly negative values for the impacts of gross outflow migration with inferior educational qualifications on enrollment into the corresponding school, suggesting the presence of a human capital disincentive effect. In particular, statistically significant coefficients are observed, implying the negative effects on college enrollment $(-0.164)$ and high school enrollment $(-0.110)$.

The estimates of $\beta_{1}$ indicate that the human capital incentive effect surpasses the human capital disincentive effect on the whole; however, this does not

15 Enrollment into college from other provinces, which we discuss in Section II, influences the percentage of students who are admitted to colleges at the provincial level. In this sense, our estimates may not correctly reflect the impact on college enrollments in native provinces. Unfortunately, this potential problem cannot be resolved due to data availability. 
Table 4 Descriptive statistics

\begin{tabular}{|c|c|c|c|c|c|c|}
\hline & \multicolumn{3}{|c|}{1990} & \multicolumn{3}{|c|}{2000} \\
\hline & Observation & Mean & $\begin{array}{l}\text { Standard } \\
\text { Deviation }\end{array}$ & Observation & Mean & $\begin{array}{l}\text { Standard } \\
\text { Deviation }\end{array}$ \\
\hline$B M I G O$ & 29 & 0.798 & 0.379 & 29 & 1.844 & 1.461 \\
\hline$B M I G N$ & 29 & 1.329 & 1.406 & 29 & 2.763 & 3.826 \\
\hline$J M I G O$ & 29 & 1.750 & 0.865 & 29 & 4.372 & 4.082 \\
\hline$J M I G N$ & 29 & 1.399 & 1.157 & 29 & 4.411 & 6.591 \\
\hline ABOVEJ MIGO & 29 & 2.057 & 0.803 & 29 & 4.269 & 3.560 \\
\hline$H M I G O$ & 29 & 2.170 & 0.999 & 29 & 3.625 & 2.805 \\
\hline$H M I G N$ & 29 & 1.288 & 0.671 & 29 & 3.320 & 4.863 \\
\hline ABOVEH MIGO & 29 & 2.680 & 0.965 & 29 & 3.848 & 2.502 \\
\hline BELOWH MIGO & 29 & 1.136 & 0.485 & 29 & 3.070 & 2.662 \\
\hline CMIGO & 29 & 5.772 & 2.409 & 29 & 4.372 & 2.267 \\
\hline$C M I G N$ & 29 & 1.735 & 1.377 & 29 & 2.649 & 3.293 \\
\hline BELOWC MIGO & 29 & 1.268 & 0.502 & 29 & 3.148 & 2.662 \\
\hline$P C G D P$ & 29 & 2035.273 & 1193.152 & 29 & 5298.984 & 3223.033 \\
\hline EDUJ & 29 & 79.711 & 10.782 & 29 & 93.773 & 4.665 \\
\hline$E D U H$ & 29 & 37.518 & 12.071 & 29 & 52.760 & 13.954 \\
\hline$E D U C$ & 29 & 7.653 & 8.771 & 29 & 24.132 & 15.842 \\
\hline UEMP & 29 & 2.532 & 1.008 & 29 & 3.477 & 0.662 \\
\hline NUMJ & 29 & 184.459 & 169.409 & 29 & 171.832 & 165.728 \\
\hline$N U M H$ & 29 & 97.894 & 138.225 & 29 & 96.769 & 149.083 \\
\hline$N U M C$ & 29 & 6.590 & 16.002 & 29 & 6.728 & 14.390 \\
\hline
\end{tabular}

necessarily mean that enhanced outflow migration was favorable for school enrollment and human capital formation at the national level in China in the 1990s. The estimated higher positive coefficients than the negative coefficients suggest that when the outflow migration rates of the more educated and the less educated grow at the same pace, more of those who are making decisions on school enrollments go on to higher levels of education. Nevertheless, as is discussed in Section II, there were imbalances in the growth of the outflow migration rates with different educational backgrounds. The increase in the migration was unevenly inclined towards high school and junior high school graduates in the 1990s, and, thus, there may be a greater human capital disincentive effect in China. For example, the regression results indicate that a 1-percent increase in the gross outflow migration rate of those with a high school education and above (ABOVEH MIGO) increases high school enrollment $(E D U H)$ by 0.26 percent, and a 1 -percent increase in the gross outflow migration rate of those with a junior high school education and below (BELOWH MIGO) decreases it by 0.11 percent. In contrast, from 1990 to 2000 , the migration rates for high school graduates and above and junior high school graduates and below grew from 2.46 to 3.87 percent and from 1.14 to 3.73 percent, respectively, at the national level. Then, it turns out that, even with the greater estimate for the human capital incentive effect than the disincentive 


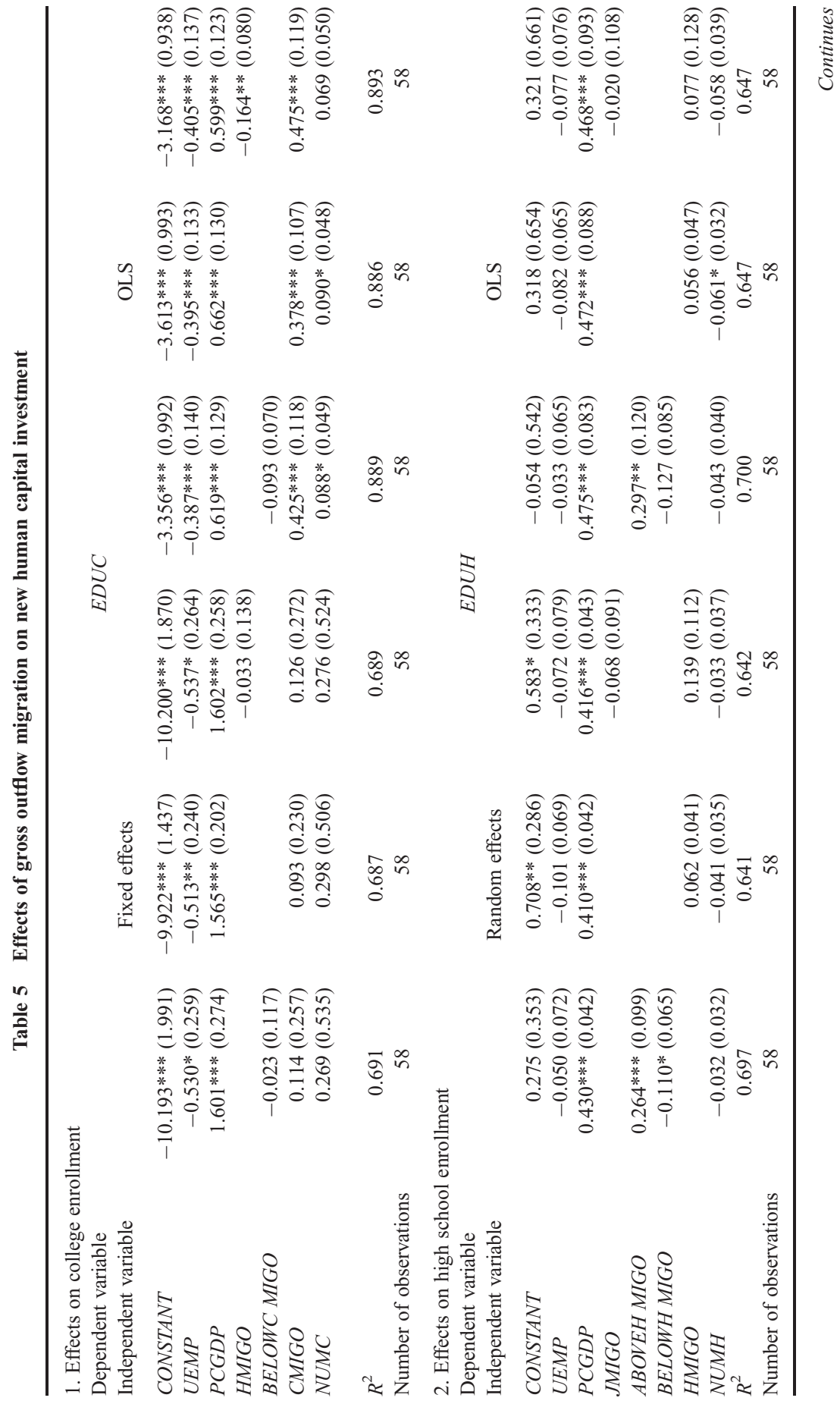




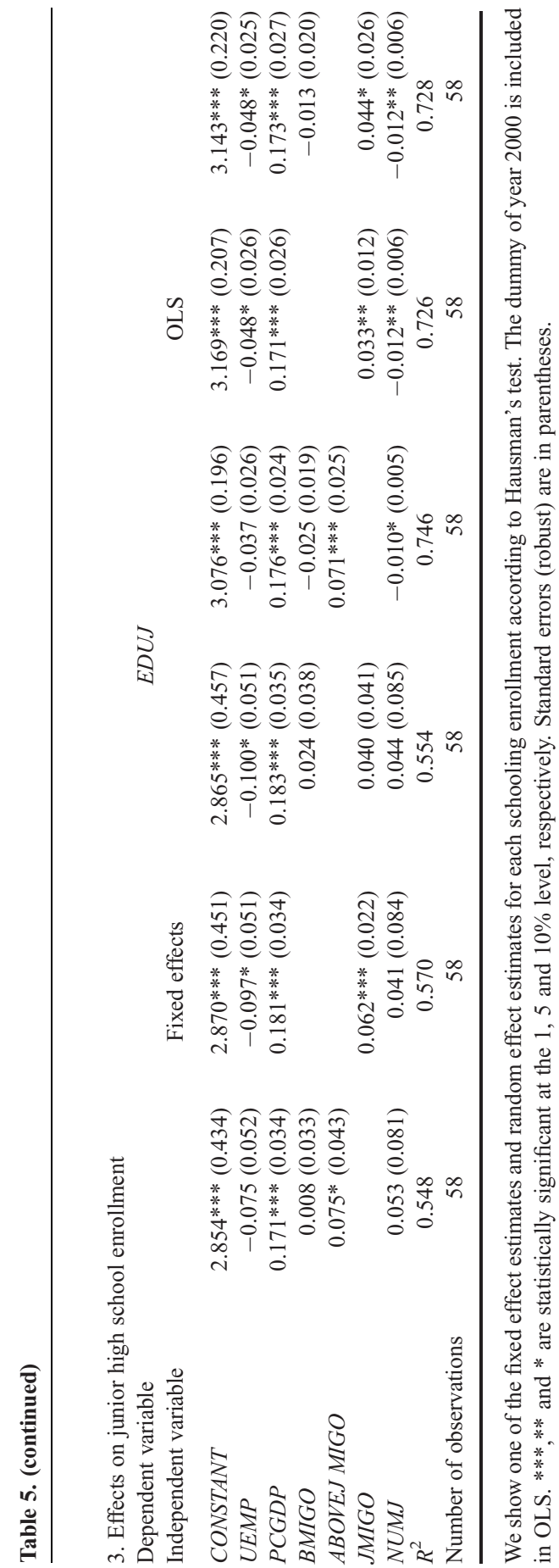

(C) 2016 East Asian Economic Association and John Wiley \& Sons Australia, Ltd 
effect, enhanced outflow migration has worked against high school enrollment. The estimates suggest that the surge of migration, particularly among the less educated groups, has reduced high school enrollment by 3.2 percentage points. ${ }^{16}$

Our estimates also report how economic conditions and accessibility to schools determine school enrollment. The estimates of $\beta_{2}$ indicate that higher income is conducive to higher advancement rates at all levels and these impacts are shown to be greater at higher education levels. We, on the other hand, observe that unemployment has an adverse effect on school enrollments, particularly into college. Greater spatial accessibility to schools, measured by the ratio of the number of schools to land area, has a positive effect on college enrollment only. ${ }^{17}$

The empirical results are, on the whole, consistent with our hypothesis of migration-oriented investment and disinvestment in higher education. The estimated coefficients indicate both the human capital incentive and disincentive effects of interprovincial migration of individuals with diverse educational levels. The absolute values of estimates suggest that the human capital incentive effect eclipses the disincentive effect in general. Nevertheless, in view of the rising migration levels among the less educated groups triggered by the regional disparities posed by the unbalanced economic growth, our results infer that China faced more adverse effects on human capital formation than favorable effects in the 1990s.

\section{Relative Labor Supply Effect}

This section explores an alternative but not mutually exclusive path, where interprovincial migration changes relative labor supply of the workers with diverse educational backgrounds, which then influences return to schooling and, accordingly, incentives to enroll into schools. This channel can be critical in the case of domestic migration which generally occurs on a far larger scale than international migration, while the monetary and psychological costs of migration and uncertainty prevent full and immediate arbitrage and, thus, some disparities in the returns to schooling across provinces persist. With respect to the case of China,

16 Since the estimate points to an increase in $E D U H$ by 0.26 percent for a 1-percent increase in ABOVEH MIGO, a 57.3 percent increase in $A B O V E H M I G O$ from 2.46 percent in 1990 to 3.87 percentin 2000 implies that the human capital incentive effect is 14.9 percent throughout the 1990s. Analogously, as the result indicates a decrease in $E D U H$ by 0.11 percent for a 1 -percent increase in BELOWHMIGO, the human capital disincentive effectis 25.0 percent when BELOWH MIGO grows by 227.2 percent from 1.14 percentto 3.73 percent. The human capital disincentive effect exceeds incentive effect by 10.1 percent, which implies a 3.2-percentage point reduction in high school enrollment, when nationwide EDUH in 1990-1992 is 31.9 percent.

17 We also seek to assess the monetary cost of education by adding the ratio of tuition costs to educational funds in all educational categories in every equation. Unfortunately, we can apply this only for the OLS estimates of 2000 (not reported) due to lack of data, and these results confirm that the estimated results reported in Table 5are robust. 
there is an argument against this mechanism: that return to schoolings remained low until mid-1990s in China as compared with peer developing countries and transition economies (Fleisher and Wang, 2005; Fleisher et al., 2005). However, as more firms removed wage grids in place under the centrally planned economy in setting wages for their workers and began hiring through the market mechanism, return to schooling increased in the 1990s (Li, 2003; Zhang et al., 2005). As a result, changes in relative labor supply brought about by large-scale interprovincial migration should come to be more relevant as a factor determining the incentive to enroll in schools in source provinces, in particular, towards 2000.

Here we focus on the net outflow migration rate, unlike the previous section which estimated human capital incentive and disincentive effects. Net outflow migration affects the relative wages of workers with different educational qualifications. Consider a net outflow of workers in an educational category (e.g. high school) from a province. This outflow causes an excess demand for workers of the corresponding category (high school), and, hence, their relative wage is increased. Furthermore, assuming that workers with diverse educational backgrounds are heterogeneous and not perfect substitutes for each other, the relative wages of workers in other educational categories (college, junior high school and lower than junior high school) are reduced. This signifies that net outflow migration can potentially impact school enrollments either positively or negatively: net outflow migration of those with a particular educational qualification (high school) encourages enrollment into the corresponding school (high school) and discourages school enrollments at higher levels (college). This mechanism is consistent with a finding by Ramcharan (2002), who shows that through increasing the skill premium, the massive inflows of European unskilled immigrants at the turn of the 20th century engendered America's sharp rise in human capital investment. Unlike the human capital incentive and disincentive effects of gross outflow migration in the previous section, net outflow migration and resultant changes in the relative labor supply may not affect the overall rate of new human capital formation at the national level, if individuals behave in a symmetric way facing excess demand and supply of workers. However, it does affect the geographical distribution of human capital after a direct brain drain by altering new human capital investment at the provincial level.

To analyze this mechanism of changes in relative labor supply caused by twoway migration of individuals with diverse educational levels, we estimate a similar model to Equation (1) but with the net outflow migration rate $(M I G N)$ instead of the gross outflow migration rate $(M I G O)$.

$$
\begin{aligned}
\mathrm{EDU}_{\mathrm{i}, \mathrm{t}}= & \beta_{0}+\beta_{1} M_{I G N} N_{\mathrm{i}, \mathrm{t}}+\beta_{2} \text { PCGDP }_{i, t}+\beta_{3} \operatorname{UNEMP}_{i, t} \\
& +\beta_{4} \text { NUMSCHOOL }_{i, t}+\left(\gamma_{i}\right)+v_{i, t} .
\end{aligned}
$$

We investigate incentives to entering into three education categories, junior high school, high school and college, separately. We estimate the effects on school 


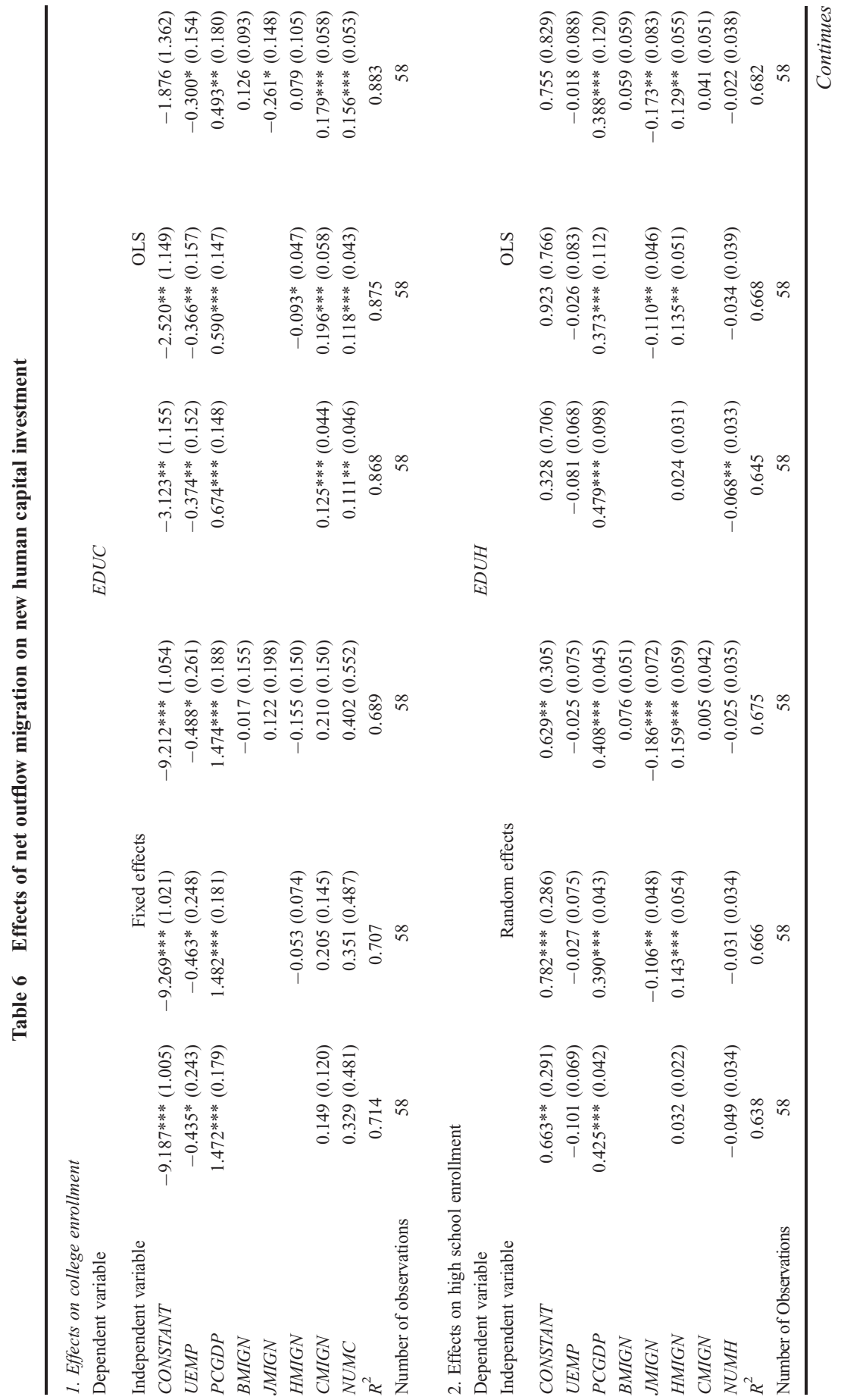




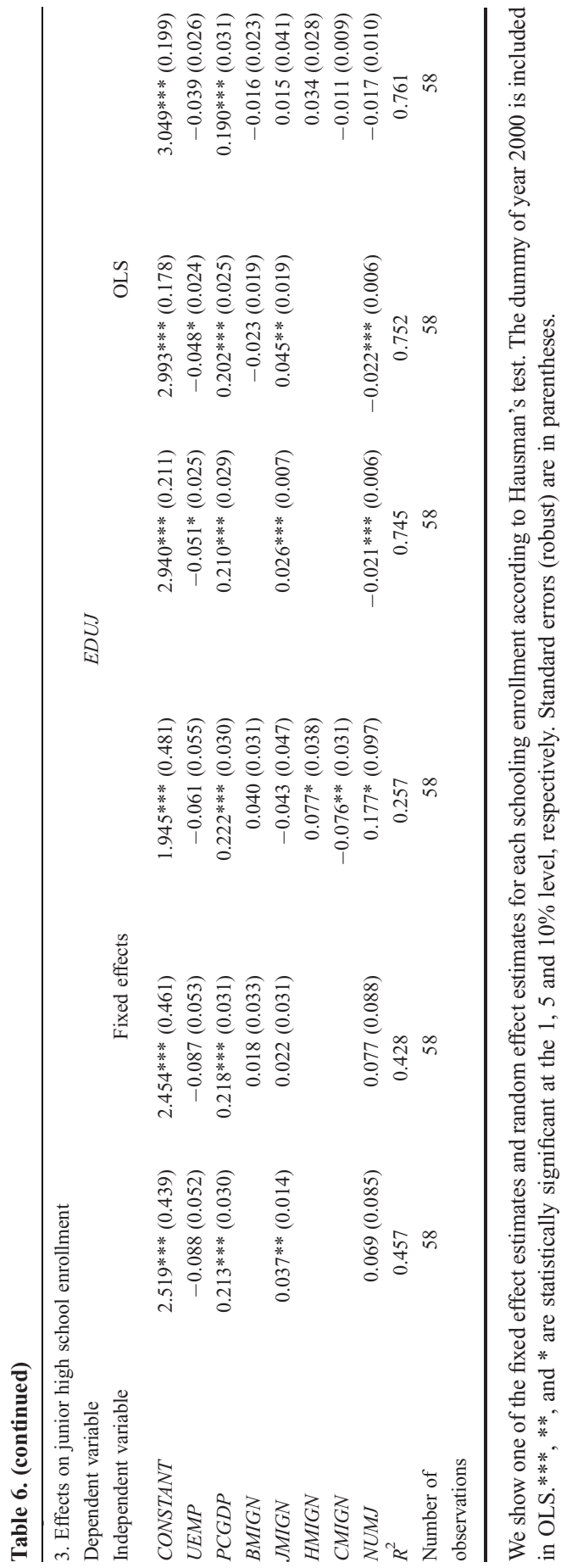

(C) 2016 East Asian Economic Association and John Wiley \& Sons Australia, Ltd 
enrollment at each of these three education categories (e.g. high school) brought about by the net outflow migration of individuals with diverse educational backgrounds in the following three cases: (i) corresponding level of education itself (high school), (ii) corresponding level of education (high school) and one level below (junior high school), ${ }^{18}$ and (iii) all the levels of education.

The estimates in Table 6 indicate both positive and negative impacts of net outflow migration on enrollments into schools at three different levels. It is shown that net outflow of migrants with a college education, a high school education and a junior high school education, respectively, enhances new human capital formation at the corresponding levels, and, thereby, mitigates the direct brain drain effects. Furthermore, we observe that a net outflow of migrants with a junior high school education deters high school enrollments. This also mitigates the direct brain drain of junior high school graduates, but it does so by discouraging new human capital investment in a higher category.

\section{Conclusions}

This paper examines the impact of interprovincial migration of individuals with diverse educational levels on the creation of human capital in source provinces in China. Unlike international migration, interprovincial migration can be a 'zero sum game' at the national level: simply transferring human capital embodied in migrants from one province to the other, if migration does not affect incentive for new human capital formation. However, this does not hold when we take into account the possibility that decisions on human capital investment are endogenous to the prospects and realizations of migration. Given the rapid increase in the mobility of workers in China in the 1990s and the varied prospects of migration based on educational background, provinces may have played a 'positive or negative sum game' rather than a 'zero sum game'.

We identify both human capital incentive and disincentive effects of gross outflow migration: better prospects of successful migration for those with higher educational backgrounds encourages residents to go on to enroll in higher education levels; increased opportunity cost of higher education induces people to hold off seeking higher levels of education when it is easier to migrate out to advanced regions with less educational achievements. Moreover, the absolute values of estimates suggest that the human capital incentive effect eclipses the disincentive

18 We, in particular, focus on the category one level below, because the incentive to attend an educational institution (high school) is naturally considered to be stronger for those who were to finish at an institution one level below (junior high school) without the positive impact on the relative wages than for those who were to finish their education at a much lower level (primary school). In addition, assuming that workers at closer educational levels are more substitutable, wages for workers at those levels would be less depressed (wages for those with a junior high school education would be less depressed than for those with only a primary school education) as a result of net outflow migration of workers in a given education category (high school). 
effect in general. Nevertheless, this does not necessarily indicate that better prospects of migration enhanced school enrollments at the national level in China in the 1990s. Interprovincial migration increased in the 1980s and 1990s when reform and opening-up policies enlarged income disparities across coastal and inland provinces and increased returns to schooling, which were suppressed under the centrally planned economy. The increase in interprovincial migration was triggered by a relaxation of residency restrictions, which first largely occurred for the wealthy and the highly educated. As a result, migration rates were much higher for college graduates in 1990, and our estimates imply that interprovincial migration of those with higher education levels contributed to human capital investment. However, in the 1990s, the sharp economic growth and resultant high labor demand in coastal regions accelerated interprovincial migration of high school and junior high school graduates despite their disadvantages under the hukou system. In view of our estimates, the increased migration of those with relatively lower educational backgrounds obstructed human capital investment in the 1990s. Indeed, notwithstanding the continued residency restrictions for high school and junior high school graduates, our results suggest that the surge in interprovincial migration on the whole has had an adverse effect on human capital investment in the source provinces from 1990 to $2000 .^{19}$

A different aspect of interprovincial migration has also been explored: massive net outflow migration, which works as a perturbation to labor markets, can alter incentives to pursue education by affecting return to schooling locally. Our estimates support both a positive impact on enrollment into corresponding schools and a negative impact on advancement to higher levels of education in source provinces, which altogether mitigates the direct brain drain effect and helps reduce the overconcentration of human capital in particular provinces.

\section{References}

Beine, M., F. Docquier and H. Rapoport, 2001, Brain drain and economic growth: Theory and evidence. J Dev Econ, 64, pp. 275-89.

Beine, M., F. Docquie and H. Rapoport, 2008, Brain drain and human capital formation in developing countries: Winners and losers. Econ J, 118, pp. 631-52.

Bhagwati, J. N. and K. Hamada, 1974, The brain drain, international integration of markets for professionals and unemployment. J Dev Econ, 1, pp. 19-42.

Borjas, G. J. and B. Bratsberg, 1996, Who leaves? The outmigration of the foreign born. Rev Econ Stat, 78, pp. $165-76$.

19 In spite of this adverse effect, the overall school enrollment rates improved in the 1990s. The percentage of primary school graduates entering into junior secondary schools increased from 74.6 percent in 1990 to 94.9 percent in 2000. The percentage of junior secondary school graduates advancing to senior secondary schools also increased from 40.6 percent in 1990 to 51.2 percent in 2000. The percentage of senior secondary school graduates being admitted to institutions of higher learning grew from 27.3 percent in 1990 to 73.2 percent in 2000. 
Borraz, F., 2005, Assessing the impacts of remittances on schooling: The Mexican experience. Glob Econ J, 5, pp. 1-30.

de Brauw, A. and J. Giles, 2005, Migrant opportunity and the educational attainment of youth in rural China. World Bank Policy Research Working Paper, No. 4526, World Bank Group, Washington, DC.

Docquier, F and H. Rapoport, 2004, Skilled migration: The prospective of developing countries. World Bank Policy Research Working Paper, No. 3382, World Bank Group, Washington, DC.

Docquier, F. and H. Rapoport, 2012, Globalization, brain drain and development. J Econ Lit, 50, pp. 681-730.

Edwards, A. C. and M. Ureta, 2003, International migration, remittances, and schooling: Evidence from El Salvador. J Dev Econ, 72, pp. 429-61.

Fleisher, B. M. and X. Wang, 2005, Returns to schooling in China under planning and reform. J Comp Econ, 33, pp. 265-77.

Fleisher, B. M., P. K. Sabirianovaand and X. Wang, 2005, Returns to skills and the speed of reforms: Evidence from Central and Eastern Europe, China and Russia. J Comp Econ, 33, pp. 351-70.

$\mathrm{Fu}, \mathrm{X}$., 2004, Limited linkage from growth engines and regional disparities in China. J Comp Econ, 32, pp. $148-64$.

Hanson, G. H. and C. Woodruff, 2003, Emigration and educational attainment in Mexico. [online; cited April 2016]. Available from URL: http://www.childmigration.net/files/Hanson_2003.pdf

Haque, N. U. and S. Kim, 1995, Human capital flight: Impact of migration on income and growth. IMF Staff Pap, 42, pp. 577-607.

Kanbur, R. and H. Rapoport, 2005, Migration selectivity and the evolution of spatial inequality. $J$ Econ Geogr, 5(January), pp. 43-57.

Li, H., 2003, Economic transition and returns to education in China. Econ Educ Rev, 22, pp. 317-28.

Lin, J. Y., G. Wang and Y. Zhao, 2004, Regional inequality and labor transfers in China. Econ Dev Cult Chang, 52, pp. 587-603.

McCulloch, R. and J. L. Yellen, 1977, Factor mobility, regional development, and the distribution of income. J Polit Econ, 85, pp. 79-96.

Miyagiwa, K., 1991, Scale economies in education and the brain drain problem. Int Econ Rev, 32, pp. $743-59$.

Mountford, A., 1997, Can a brain drain be good for growth in the source economy? J Dev Econ, 53, pp. 287-303.

NBS (National Bureau of Statistics) (NBS), 1999, Comprehensive Statistical Data and Materials on Fifty Years of New China. NBS, Beijing, China.

NBS (National Bureau of Statistics), various issues, China Population Statistics Yearbook. NBS, Beijing, China.

NBS (National Bureau of Statistics), various issues, China Statistical Yearbook. NBS, Beijing, China.

Ramcharan, R., 2002, Migration and human capital formation: Theory and evidence from the U.S. high school movement. IMF Working Paper02/123. IMF, Washington, DC.

Stark, O., C. Helmenstein and A. Prskawetz, 1997, A brain gain with a brain drain. Econ Lett, 55, pp. $227-34$.

Stark, O., C. Helmenstein and A. Prskawetz, 1998, Human capital depletion, human capital formation, and migration: Ablessing or a "Curse"? Econ Lett, 60, pp. 363-7.

Whalley, J. and S. Zhang, 2007, A numerical simulation analysis of (Hukou) labor mobility restrictions in China. $J$ Dev Econ, 83, pp. 392-410.

Yang, D. T., 2005, Determinants of schooling returns during transition: Evidence from Chinese cities. J Comp Econ, 33, pp. 244-64.

Yang, D., 2008, International migration, remittances, and household investment: Evidence from Philippine migrant's exchange rate Shocks. Econ J, 118, pp. 591-630.

Zhang, J., Y. Zhao, A. Park and X. Song, 2005, Economic returns to schooling in urban China, 1988 to 2001. J Comp Econ, 33, pp. 730-52.

(C) 2016 East Asian Economic Association and John Wiley \& Sons Australia, Ltd 


\section{Appendix: Theoretical Model}

A simple model is developed to sketch how prospects of migratioxn, when they are dependent on educational backgrounds, bear upon new human capital formation. This is an extension of Beine et al. (2001) but different in considering the prospect of migration for the uneducated group explicitly. We depict optimal behaviors of two-period lived agents with heterogeneous learning abilities in determining school enrolment, which is swayed by prospects of migration. During the youth period, heterogeneous agents have opportunities to allocate a share of time to education, which increases their human capital levels in the adult period disproportionately: agent-specific learning ability determines gain from education. In the adult period, agents have chances to emigrate to where they receive a wage premium. However, uncertainty is involved in the process of migration and, in particular, chances of successful migration hinge on educational achievement. Therefore, forward-looking heterogeneous agents make decisions on school enrollment in their youth period taking into account potential gains from education as well as prospects of migration with and without education, being fully aware of their own learning abilities.

Agents from generation $t$ are identically endowed with human capital $\left(h_{t}^{i}=h_{t}\right)$ and have opportunities to attend school in their youth period. When an agent $i$ decides to enroll in school, he/she devotes a fixed fraction of time in education $\left(e_{t}^{i}=\bar{e}\right)$. Otherwise, no cost is incurred $\left(e_{t}^{i}=0\right)$. The schooling changes the agents' human capital levels in their adult period. Agents are heterogeneous in their learning abilities $\left(a^{i}\right)$ which determine how agents are effective in transforming the fixed time spent in education to human capital:

$$
h_{t+1}^{i}=\left(1+a^{i} e^{i \beta}\right) h_{t},
$$

where $0<\beta<1$ and $\mathrm{a}^{\mathrm{i}}$ is uniformly distributed on a probability space $[\underline{a}, \bar{a}]$. Note that, if agent $i$ chooses not to attend school $\left(e_{t}^{i}=0\right)$, the human capital level remains unchanged in the adult period $\left(h_{t+1}^{i}=h_{t}\right)$.

Agents have chances to migrate from their home into an advanced exterior region in their adult period where rewards for human capital are proportionally higher. This wage premium comes from the higher level of economic development achieved in the destination district and, thus, is exogenous to agents' decision-making. The reward for the human capital in the destination district with and without schooling is given, respectively, by:

$$
\begin{gathered}
w h_{t+1}^{i}=w\left(1+a^{i} \bar{e}^{\beta}\right) h_{t} \quad\left(\text { with schooling; } e_{t}^{i}=\bar{e}\right) \\
w h_{t+1}^{i}=w h_{t} \quad\left(\text { without schooling; } e_{t}^{i}=0\right)
\end{gathered}
$$

where $w$ represents the wage premium in the advanced exterior net of any monetary and non-monetary costs associated with migration $(w>1)$. 
If agents were free from any uncertainty in migration, all would have immigrated into the exterior induced by higher rewards. However, agents face uncertainty, which holds the probabilities of migration smaller than the unity. The central and local governments can place a curb on immigration through policy. Because governments discriminate against the non-educated group in giving permission, the probability of successful migration is dependent on educational background. We thus denote prospects of successful migration with and without education by $p$ and $q$, respectively $(0 \leq q \leq p \leq 1)$.

Each agent optimally determines whether to attend school or not through evaluating advantages and costs of education. The advantages are two folds: higher human capital stock is available in the adult period and there are potentially better prospects of migration, which increases the expected return to human capital. These gains can be greater or smaller depending on the learning ability of the agent $\left(a^{i}\right)$, while the cost of education is fixed $\left(\bar{e} h_{t}\right)$. For simplicity, we assume that agents are risk neutral and discount expected return in their adult period by a constant rate $(r)$. Then, for agent $i$, the present value of being educated $\left(P V_{e}\right)$ is:

$$
P V_{e}=(1-\bar{e}) h_{t}+\frac{p w\left(1+a^{i} \bar{e}^{\beta}\right) h_{t}}{1+r}+\frac{(1-p)\left(1+a^{i} \bar{e}^{\beta}\right) h_{t}}{1+r}
$$

and the present value of not being educated $\left(P V_{n}\right)$ is

$$
P V_{n}=h_{t}+\frac{q w h_{t}}{1+r}+\frac{(1-q) h_{t}}{1+r}
$$

Because agent $i$ attends school if and only if $P V_{e} \geq P V_{n}$, the condition under which he/she attends school is given by:

$$
a^{i} \geq a_{E} \equiv \frac{(1+r) \bar{e}^{(1-\beta)}-(p-q)(w-1) \bar{e}^{(-\beta)}}{1+p(w-1)},
$$

where we denote $a_{E}$ as the critical level of learning ability which makes an agent indifferent between attending school or not.

Our interests are on how changes in the prospects of migration alter the incentive to enroll in school, when prospects of migration are dependent on educational backgrounds. Therefore, we suppose an intermediate case when some agents have an incentive to enroll in school and others do not (i.e. $\bar{a}>a_{E}>\underline{a}$ ). To show that higher prospects of successful migration with schooling encourage school enrollment, we derive the change in the critical level of learning ability when prospect of migration with schooling $(p)$ becomes marginally higher. That is, we have, for any arbitrary $q(\geq 0)$ : 


$$
\frac{\partial a_{E}}{\partial p}=\frac{-(w-1) \bar{e}^{(-\beta)}\{1+(1+r) \bar{e}+q(w-1)\}}{\{1+p(w-1)\}^{2}}<0 .
$$

A better prospect of migration for the educated group pushes up the present value of being educated due to proportionally higher returns on the human capital in the destination, and, thus, the critical level of learning ability is lowered. This means that some agents in the uneducated group are now induced to attend school. Therefore, better prospects of migration with higher educational background per se encourage new human capital formation.

Analogously to this, it is shown that better prospects of migration without schooling discourage school enrollment. We have, for any arbitrary $p(\geq 0)$ :

$$
\frac{\partial a_{E}}{\partial q}=\frac{(w-1) \bar{e}^{(-\beta)}}{1+p(w-1)}>0 .
$$

This shows that a higher probability of successful migration for the uneducated group pushes up the opportunity cost of education, and, thus, fewer agents come to be induced to spend resources on human capital investment. Some of the agents, who previously considered that it was worth paying the cost of education, are now not willing to enroll in school, when they observe a higher chance of successful migration without schooling. This signifies that a better prospect of migration without educational background per se discourages school enrollment. 